\title{
Single-cell MALDI Tandem Mass Spectrometry: Unambiguous Assignment of Small Biomolecules from Single Chlamydomonas reinhardtii Cells
}

\author{
Jasmin Krismer§, Robert F. Steinhoff, and Renato Zenobi* \\ §SCS-DSM Award for best poster presentation in Analytical Sciences
}

\begin{abstract}
The analysis of compounds from single cells is a major challenge in analytical life science. Labeling strategies, for instance fluorescence detection, are well established for measuring proteins with single cell sensitivity, but they mostly fail to detect small molecules. More recently mass spectrometry has entered the realm of single cell sensitivity and enables the label-free and highly parallelized detection of small biomolecules from single cells. The assignment of signals detected in single cells, however, generally has to rely on measurements in whole cell culture extracts. Isobaric structures, contaminations, higher noise levels and the high variability in the abundance of peaks between single cells complicate the assignment of peaks in single-cell spectra. Tandem mass spectrometry would be very useful for compound identification via mass spectrometry directly in singlecell analyses. Here we present the first single cell tandem mass spectra collected using matrix-assisted laserdesorption/ionization. The spectra obtained allow the assignment of most compounds detected in the spectra. We also show that the fragmentation is not restricted to the most abundant peaks in the spectra, but over a dynamic range of more than one order of magnitude.
\end{abstract}

Keywords: Collision-induced-dissociation · Matrix-assisted laser-desorption/ionization · Single-cell mass spectrometry $\cdot$ Tandem mass spectrometry

\section{Introduction}

Individual cells are the smallest functioning unit of life and a key challenge in analytical life science. The analytical scientist is challenged by the high sensitivity and selectivity required for the analysis of single cells. ${ }^{[1]}$ The biologist, on the other hand, seeks to understand the individual cell within the biological context of its population or tissue, which adds high throughput to the list of challenges for analytical methods to overcome. There are plenty of single-cell techniques in the area of DNA, ${ }^{[2,3]} \mathrm{RNA}^{[4,5]}$ and protein analysis ${ }^{[6,7]}$ that have found their way into biologists' labs. These techniques benefit from the amplification tools adopted from molecular biology and the high linear dynamic range and sensitivity of fluorescent probes.

However, few such tools exist for the analysis of small molecules from single cells, ${ }^{[8]}$ despite the fact that there is a great

${ }^{*}$ Correspondence: Prof. Dr. R. Zenobi Department of Chemistry and Applied Biosciences ETH Zurich

Vladimir-Prelog-Weg 3, CH-8093 Zurich

E-mail: zenobi@org.chem.ethz.ch need for phenotypic and metabolic characterization of single cells, especially since changes in genomes and transcriptomes are often poor predictors of cellular phenotypes. ${ }^{[9]}$ Mass spectrometry has made great progress with respect to sensitivity and resolution in the past decades. Matrix-assisted laser desorption/ionization (MALDI) mass spectrometry ${ }^{[10]}$ in particular can provide both the high throughput and the sensitivity needed for the analysis of large numbers of single cells. ${ }^{[11]}$ Analyzing complex and dynamic biological systems such as cells, however, requires not just detection of masses but also the assignment of the signals detected to functionally relate these to biological processes.

Tandem mass spectrometry is an important part of the methodological toolbox of a mass spectrometrist for several reasons. ${ }^{[12]}$ First, different constitutional isomers can be attributed to a single isobaric signal, which makes it possible to identify molecules using characteristic fragments. Second, contamination from different sources like solvents, the cell culture medium, cell manipulating devices or the MALDI-matrix can give rise to interferences that show the same or highly similar masses. This effect is especially important in single-cell mass spectrometry because the weight of single cells is in the range of $10^{-12}-10^{-15}$ grams. ${ }^{[13,14]}$ Third there is great variability in the relative abundance of molecules between single cells, which can complicate the peak assignment. Unfortunately the MS/MS capabilities of mass spectrometry approaches for single cell analysis have very much lagged behind.

Recently we reported a method for the high-throughput analysis of single cells for Chlamydomonas reinhardtii, a green freshwater algae and a well-studied model organism in photosynthesis and biofuel research. ${ }^{[15]}$ The method allowed the parallel detection and relative quantitation of more than 20 assigned peaks from different lipid classes with high throughput. MS/ MS capabilities would greatly enhance the explanatory power based on higher confidence in peak assignment.

Here, we present the first ever MS/ MS spectra collected from single cells using MALDI as an ionization method. The cells were analyzed using 2,5-dihydroxybenzoic acid (DHB) as a matrix, in positive ion mode. The method allowed us to assign about 15 compounds in our spectra belonging to different lipid and pigment classes. The assignments based on the single cell tandem mass spectra are in good agree- 
ment with spectra obtained by analyzing lipid extracts, as well as the relevant molecular biology literature. ${ }^{[16-18]}$

\section{Experimental Section}

\section{Chemicals}

2,5-dihydroxybenzoic acid (DHB) was purchased from Sigma-Aldrich. Chlorophyll a (from Anacystis nidulans), chloroform (>99.8\%), acetone (puriss. p.a., $\geq 99.5 \%$ ) and 2-propanol (puriss., $\geq 99.5 \%$ ) were purchased from Sigma Aldrich, Switzerland. Water (Optima ${ }^{\circledR}$ LC/ MS grade) was purchased from FisherChemicals. Hutners trace element solution for cell culture media preparation was obtained from the Chlamydomonas Resource Center (St. Paul, MN, USA)

\section{MS/MS of Lipid Extracts}

A lipid extract was performed with the Bligh-Dyer method ${ }^{[19]}$ using C. reinhardtii wild-type strain CC-125 obtained from the Chlamydomonas Resource Center, $\mathrm{St}$ Paul, MN. The cells were cultured in trisacetate-phosphate medium. ${ }^{20]}$ To aid the extraction the cells were sonicated for 30 seconds. The chloroform phase was collected and stored at $-20{ }^{\circ} \mathrm{C}$. Then the chloroform was evaporated and the lipids solubilized in aqueous acetone (80 vol\% acetone, $20 \mathrm{vol} \%$ water). The samples were mixed with DHB $(10 \mathrm{mg} / \mathrm{mL}$ in $80 \%$ aqueous acetone) on the MALDI target (384 Opti-TOF $123 \mathrm{~mm} \times 61 \mathrm{~mm} \mathrm{SS}$, ABSciex, Toronto) in a sandwich fashion $(0.5 \mu \mathrm{L}$ DHB $-0.5 \mu \mathrm{L}$ lipid extract $-0.5 \mu \mathrm{L}$ DHB). The MS/MS method used for extracts was identical to the one described below.

\section{Sample Preparation for Single-cell MS/MS}

Wild-type $C$. reinhardtii cells (strain CC125) were centrifuged $(3500 \times \mathrm{g}$ for $5 \mathrm{~min}$ ) three times and resuspended in water. The cells were placed on a microstructured array for MALDI mass spectrometry as reported previously.[15] In short, the array consists of $55 \times 26$ spots of $300 \mu \mathrm{m}$ diameter each spaced by $720 \mu \mathrm{m}$ on a stainless steel plate. A layer of matrix was added first, followed by deposition of the washed cells into the spots (Fig. 1A). Cellular metabolism was quenched immediately by immersing the entire array into liquid nitrogen. Extraction of analytes and co-crystallization with the matrix is achieved by recurrent extraction adding $5 \times 5 \mathrm{~nL}$ of $10 \mathrm{mg} / \mathrm{mL}$ of DHB dissolved in $80 \%$ aqueous acetone and letting the spots crystallize after each step. Fluorescence scans at $630 \mathrm{~nm}$ excitation and $670 \mathrm{~nm}$ emission were collected of the blank slide, of the cells after quenching, and after matrix application.
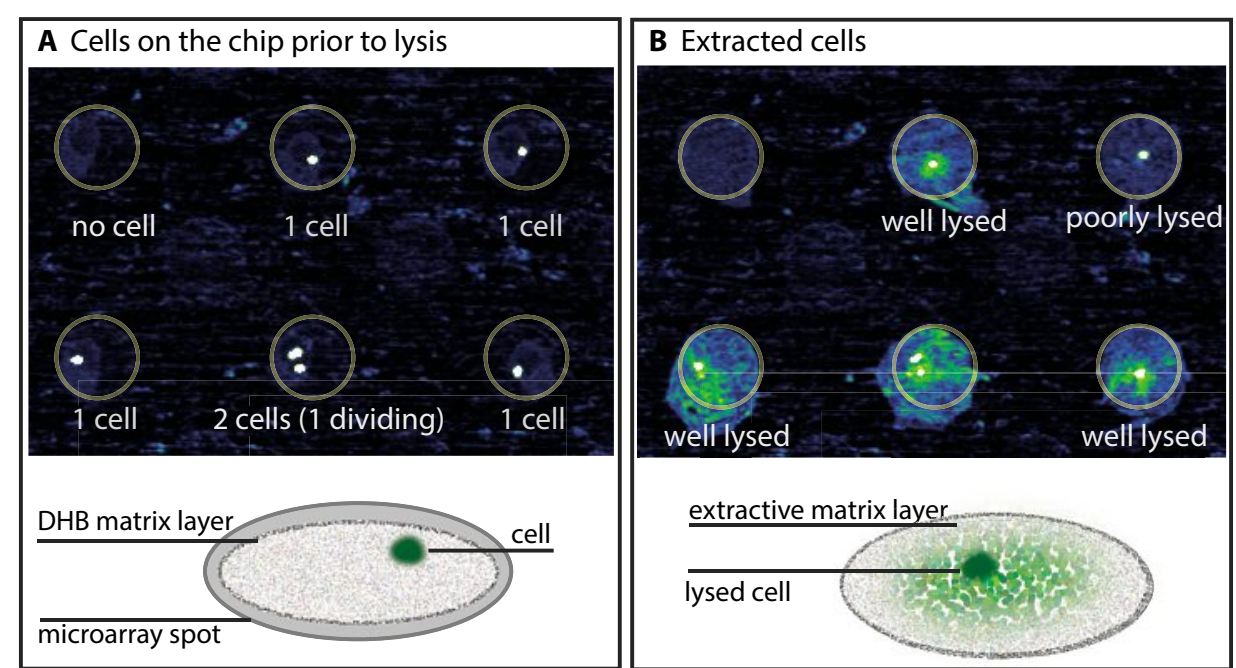

Fig. 1. Sample preparation procedure for single-cell MS/MS. Chlorophyll autofluorescence is measured at $630 \mathrm{~nm}$ excitation and $670 \mathrm{~nm}$ emission. Both of the images are scaled identically for better visibility (0-3000 instead of 0-65000) and falsely colored. The diameter of a spot is $300 \mu \mathrm{m}$. Cells are around $10 \mu \mathrm{m}$ but appear larger due to over-scaling and scattering. A: The autofluorescent cells are imaged on the slide prior to lysis to determine the number of cells in each spot. As shown in the graphical abstract below a layer of matrix is applied prior to applying the cells. B: Scanning the slides after co-crystallization can monitor the success of cell lysis. Matrix autofluorescence is negligible. Only spots containing well-lysed cells should be used for single-cell MS/MS experiments.

\section{Single-cell MS/MS}

The tandem mass spectra were recorded on a reflectron MALDI-TOF instrument (AB Sciex 5800, Toronto, CA). The spots for MS/MS were selected from the plates based on the fluorescence scans. Spectra were collected from spots showing single cells in the fluorescence scan after quenching. To confirm the fact that the signal is produced only in the presence of cells MS/ MS were recorded for the same precursor mass on spots showing no cells. In none of the cases did we detected fragments of cellular analytes in the absence of cells. The MALDI parameters used were: a delayed extraction time of $300 \mathrm{~ns}$, a laser intensity of 5500 a.u. and a laser repetition rate of $1000 \mathrm{~Hz}$. In all cases spectra were collected with and without metastable suppression. Precursors were isolated using a mass window of $\pm 1.5 \mathrm{Da}$, using the QuanTis timed ion selector of the reflectron TOF system operated with a TIS offset of $1.5 \mathrm{~mm}$.

\section{Data Analysis}

Peak picking was performed according to a $S / N \geq 10$ criterion. Spectra were calibrated externally using chlorophyll a as a reference. The spectra were smoothed using the default settings in the Data Explorer software (ABSciex, Toronto).

\section{Results and Discussion}

The tandem mass spectrometry method was optimized on a chlorophyll a standard and a lipid extract of $C$. reinhardtii. The lipid composition of $C$. reinhardtii is well studied, since the species is both a model organism in photosynthesis and a candidate for biofuel production. From an experimental perspective one of the key advantages in using the algae as a model for optimizing and developing a single cell method is that due to its autofluorescent pigments in the form of chlorophylls it is possible to visualize cell lysis, a key step for successful single cell mass spectrometry. ${ }^{[15]}$ Two aspects are very important here: the first is to make sure that the actual measurement is taken on a single cell. In the current procedure the cells are placed on a microarray by spotting a cell culture at an optimized cell density. This procedure leaves most spots occupied with single cells, which can be identified, based on fluorescence scans (Fig. 1A). However, some spots remain empty while multiple cells occupy others. These spots are discarded for analysis. The second key step is lysis and co-crystallization (Fig. 1B). Only spots that show well-lysed cells as shown in Fig. 1 are considered for MS/MS. Poorly lysed cells may still show signals in MS mode, but these are generally too low in intensity to perform MS/MS experiments.

Relying on the sample preparation protocol for single-cell MALDI optimized for $C$. reinhardtii we were able to assign 16 compounds to 14 mass spectral peaks (Table 1) by performing single-cell MS/ MS measurements. The assignments are backed up by literature. The most prominent signal in the single-cell spectra is the pigment chlorophyll a. However due to the presence of DHB, which is an acid, the extraction of the lipids is carried out under 
low $\mathrm{pH}$ conditions. This leads to a release of the $\mathrm{Mg}^{2+}$ ion from the porphyrin macrocycle. Chlorophyll a is therefore detected as pheophytin a $\left(\left[\mathrm{M}-\mathrm{Mg}^{2}+3 \mathrm{H}\right]^{+}=871.57\right.$ Da) using DHB as a matrix. ${ }^{[17,21]}$ This is also true for chlorophyll b $\left(\left[\mathrm{M}-\mathrm{Mg}^{2}+3 \mathrm{H}\right]^{+}\right.$ $=885.55 \mathrm{Da})$. The single-cell MS/MS of chlorophyll a is dominated by the signal at 593.28 Da due to the loss of the phytol chain (Fig. 2A and 2D). Chlorophyll b fragmentation leads to the formation of 607.25 Da fragment due to phytol loss. Since chlorophylls are absorbing the wavelength of the MALDI laser at $355 \mathrm{~nm}$ both CID as well as in-source decay contribute to fragmentation. An increase in laser intensity was found to enhance fragmentation even in the absence of CID gas, which supports this interpretation (data not shown).

Furthermore, the spectra show all of the most abundant lipids, which can be detected in positive ion mode, both from the plastidic, i.e. of organellar origin and extraplastidic membrane systems. Plastidic membrane systems that include the thylakoid membranes, in which the photosynthetic complexes are embedded, mainly consist of the galactolipids mono- and digalactosyl-diacylglyceol (MGDG and DGDG) and sulfolipids in the form of sulfoquinovosyl-diacylglycerol (SQDG). ${ }^{[18]}$ Since the extraction protocol was optimized for chlorophyll, it is reasonable that the major membrane constituents are co-extracted. MGDG and DGDG can be detected in the form of sodium $\left(\left[\mathrm{M}+\mathrm{Na}^{+}\right]^{+}\right)$or potassium $\left(\left[\mathrm{M}+\mathrm{K}^{+}\right]^{+}\right)$adducts using MALDI-MS as

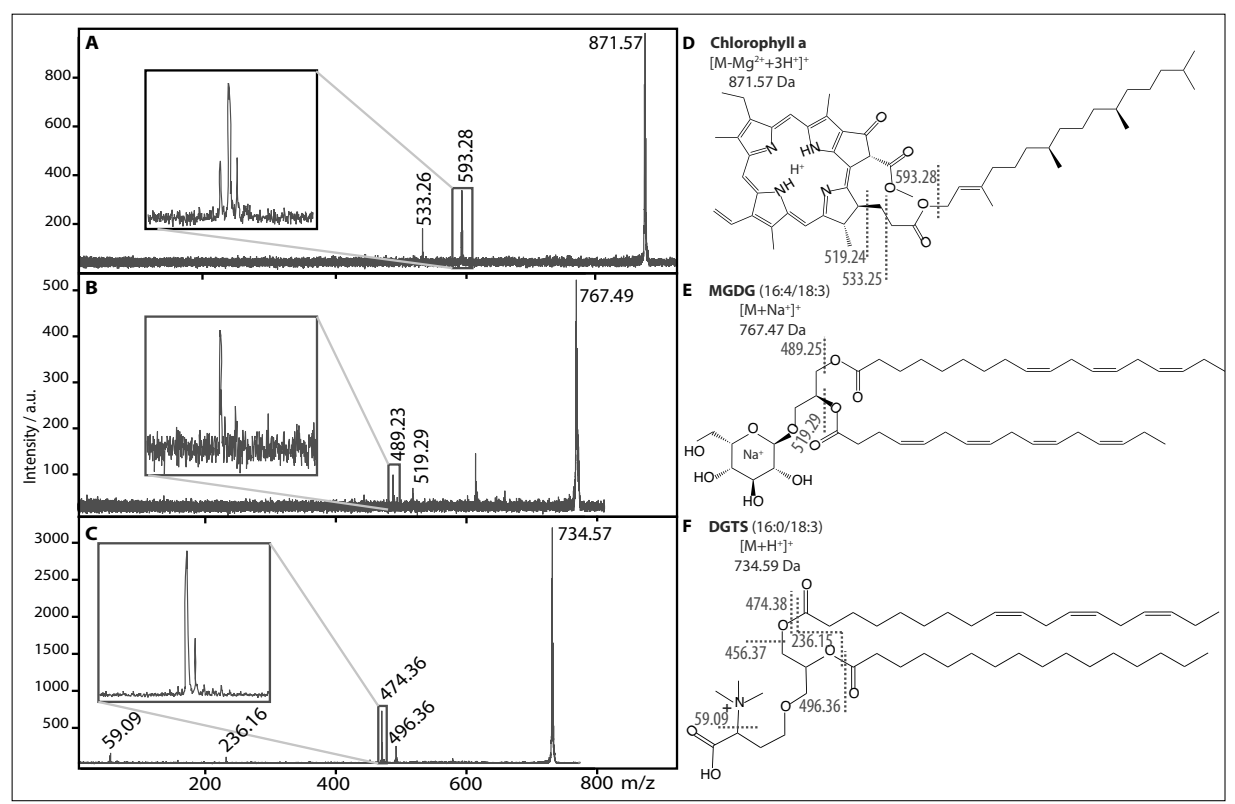

Fig. 2, Single-cell MS/MS and corresponding chemical structures of different compound classes detected in single cells. A/D: Single-cell MS/MS of chlorophyll a the structure showing the fragmentation explaining the most abundant signals in the MS/MS spectra. B/E: SC-MS/MS and the chemical structure of MGDG, a plastidic galactolipid. C/F: SC-MS/MS and chemical structure of a DGTS, an extraplastidic lipid. The highly stabilized charge leads to the detection of the lipid headgroup even in single-cell spectra. The positions of the two fatty acids (sn1 or sn2) cannot be determined using MS/MS but are adapted from literature. ${ }^{[16]}$

previously reported by Vieler et al. ${ }^{[21]}$ In the single-cell mass spectra the sodium adducts are most prominent. The SC-MS/MS spectra of both MGDG (see Fig. 2B and 2E) and DGDG lipids are characterized by neutral loss of the fatty acid side chains. ${ }^{[22]}$ Despite the fact that MGDG (16:4/18:3) makes up for almost $80 \%$ of the MGDG lipid, which in turn contributes about $50 \%$ of the total thylakoid lipid, the relative intensity of the peak is relatively low at $18 \%$. This can be attributed to a lower ionization efficiency due to the sodium adduct formation.

The major extraplastidic lipid classes are the diacylglyceryl-trimethylhomoser-

Table 1. List of compounds assigned by SC-MS/MS in Chlamydomonas reinhardtii using DHB in positive ion mode. Relative intensities relate to single-cell MS spectra collected from the same population. Numbers in brackets relate to the fatty acid composition (carbon number: number of double bonds) the position of the fatty acid or the position of the double bonds cannot be determined using single-cell MS/MS.

\begin{tabular}{|c|c|c|c|c|c|c|}
\hline & metabolite name & $\begin{array}{l}\text { rel. } \\
\text { int. }\end{array}$ & species detected & parent mass & main fragment & other fragments \\
\hline \multirow{2}{*}{ Pigments } & Chlorophyll a & 100 & {$\left[\mathrm{M}-\mathrm{Mg}^{2+}+3 \mathrm{H}^{+}\right]^{+}$} & 871.57 & 593.28 & $533.25,519.30$ \\
\hline & Chlorophyll b & 34 & {$\left[\mathrm{M}-\mathrm{Mg}^{2+}+3 \mathrm{H}^{+}\right]^{+}$} & 885.55 & 607.25 & $547.24,533.29$ \\
\hline \multirow[t]{5}{*}{ Galactolipids } & MGDG (16:4/18:3) & 18 & {$\left[\mathrm{M}+\mathrm{Na}^{+}\right]^{+}$} & 767.47 & 489.24 & 519.28 \\
\hline & DGDG (18:3/16:3) & 19 & {$\left[\mathrm{M}+\mathrm{Na}^{+}\right]^{+}$} & 931.53 & 653.27 & 681.28 \\
\hline & DGDG (18:2/16:3) & 15 & {$\left[\mathrm{M}+\mathrm{Na}^{+}\right]^{+}$} & 933.55 & 653.28 & 683.45 \\
\hline & DGDG (18:3/16:0) & 9 & {$\left[\mathrm{M}+\mathrm{Na}^{+}\right]^{+}$} & 937.58 & 659.31 & 681.22 \\
\hline & DGDG (18:2/16:0) & 9 & {$\left[\mathrm{M}+\mathrm{Na}^{+}\right]^{+}$} & 939.6 & 659.3 & 683.24 \\
\hline \multirow[t]{7}{*}{ Homoserine lipids } & DGTS (16:0/18:4) & 51 & {$\left[\mathrm{M}+\mathrm{H}^{+}\right]^{+}$} & 732.58 & 474.33 & $494.30,236.16$ \\
\hline & DGTS (16:0/18:3) & 49 & {$\left[\mathrm{M}+\mathrm{H}^{+}\right]^{+}$} & 734.59 & 474.37 & $\begin{array}{l}496.38,236.16, \\
474.37,456.34\end{array}$ \\
\hline & DGTS (16:0/18:2) & 21 & {$\left[\mathrm{M}+\mathrm{H}^{+}\right]^{+}$} & 736.61 & 474.36 & 498.33 \\
\hline & DGTS (18:3/18:4) & 19 & {$\left[\mathrm{M}+\mathrm{H}^{+}\right]^{+}$} & 754.55 & 496.42 & 494.42 \\
\hline & $\begin{array}{l}\text { DGTS (18:3/18:3), } \\
\text { DGTS (18:4/18:2) }\end{array}$ & 20 & {$\left[\mathrm{M}+\mathrm{H}^{+}\right]^{+}$} & 756.57 & 496.32 & $\begin{array}{l}498.36,494.29, \\
236.12\end{array}$ \\
\hline & DGTS (18:2/18:3) & 26 & {$\left[\mathrm{M}+\mathrm{H}^{+}\right]^{+}$} & 758.6 & 496.36 & 498.39 \\
\hline & $\begin{array}{l}\text { DGTS (18:2/18:2), } \\
\text { DGTS (18:1/18:3) }\end{array}$ & 18 & {$\left[\mathrm{M}+\mathrm{H}^{+}\right]^{+}$} & 760.61 & 498.36 & $496.45,500.38$ \\
\hline
\end{tabular}


ines (DGTS) which functionally replace phosphatidylcholines in $C$. reinhardtii. ${ }^{[18]}$ The DGTS lipids show a great variety of fatty acid side chains in the single-cell spectra (Table 1, Fig. 2C and 2F). One reason for this lipid class to be readily observed might be the high ionization efficiency of the highly polar lipid headgroup. The trimethylhomoserine-headgroup itself as well as various fragments generated by the loss of fatty acid side chains can also be detected in single-cell MS/MS spectra (Fig. 3). In contrast to the galactolipids the side chain fragmentation leads both to the fatty acid neutral loss and the cleavage of the acyl group with the latter being more prominent in the single-cell MS/MS spectra. The relative abundance of the different DGTS species agrees well with previously reported values. ${ }^{[16]} \mathrm{A}$ unique advantage of applying MS/MS is that fragmentation of the side chains allows the assignment of multiple isobaric species. We were able to assign multiple isobars for the signal at 756.57 Da (DGTS (18:2/18:2) and DGTS (18:1/18:3)) and 760.61 Da (DGTS $(18: 3 / 18: 3)$ and DGTS (18:4/18:2)) respec-

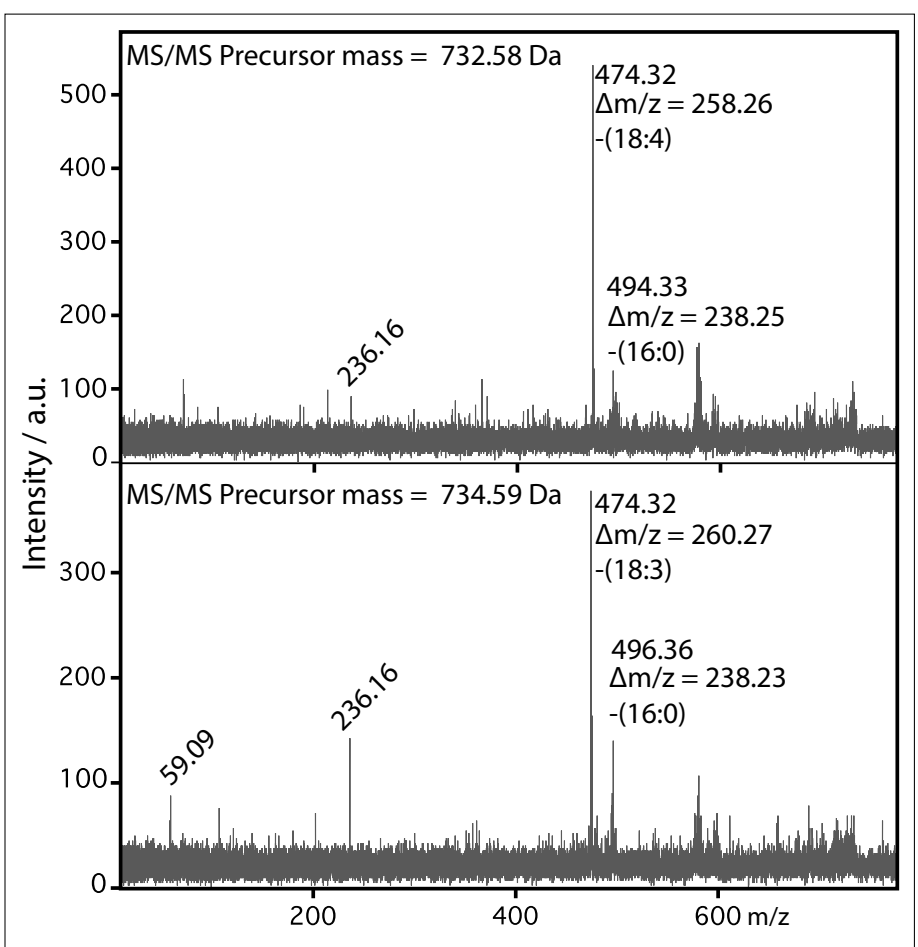

tively. One explanation for the detection of multiple isobars in the case of $756.57 \mathrm{Da}$ and 760.61 Da is the similar abundance of the two contributing DGTS species. ${ }^{[16]}$

\section{Conclusions}

Peak assignment in single-cell spectra is a challenge for the advancement of single-cell mass spectrometry techniques. The certainty of the actual assignment based on fragment detection - despite all database searches and high mass accuracy is unsurpassed. The successful implementation of MS/MS experiments on the single-cell level as shown here reflects the progress made with respect to sensitivity and reproducibility, and adds an important amendment to single-cell MALDI mass spectrometry.

\section{Acknowledgement}

We would like to thank the physics workshop of ETH Zurich and Dr. Rolf Brönnimann from EMPA Dübendorf for the help in producing the microarrays for MALDI-MS. We would like to thank Dr. Jens Sobek from the Functional Genomics Center Zurich for the assistance using the microarrayer for the sample preparation and Prof. Dr. Julia Vorholt from the Microbiology Institute at ETH Zurich for allowing us to use their sterile bench.

Received: January 12, 2016

[1] E. Strauss, Nat. Chem. Biol. 2010, 6, 873

[2] H. Li, U. B. Gyllensten, X. F. Cui, R. K. Saiki, H. A. Erlich, Nature 1988, 335, 414.

[3] R. S. Lasken, Curr. Opin. Microbiol. 2007, 10, 510.

[4] F. Tang, C. Barbacioru, Y. Wang, E. Nordman, C. Lee, N. Xu, X. Wang, J. Bodeau, B. B Tuch, A. Siddiqui, K. Lao, M. A. Surani, Nat. Meth. 2009, 6, 377

[5] S. Islam, U. Kjällquist, A. Moliner, P. Zajac, J.-B. Fan, P. Lönnerberg, S. Linnarsson, Nat. Protocols 2012, 7, 813.

[6] J. Lippincott-Schwartz, G. H. Patterson, Science 2003, 300, 87

[7] B. N. G. Giepmans, S. R. Adams, M. H. Ellisman, R. Y. Tsien, Science 2006, 312, 217.

[8] R. Zenobi, Science 2013, 342, 1243259.

[9] M. D. Ritchie, E. R. Holzinger, R. Li, S. A. Pendergrass, D. Kim, Nat. Rev. Genet. 2015, 16,85 .

[10] M. Karas, D. Bachmann, U. Bahr, F. Hillenkamp, Int. J. Mass Spectrom. Ion Proc. 1987, 78, 53.

[11] T. H. Ong, D. J. Kissick, E. T. Jansson, T. J. Comi, E. V. Romanova, S. S. Rubakhin, J. V. Sweedler, Anal. Chem. 2015, 87, 7036.

[12] F. McLafferty, Science 1981, 214, 280.

[13] T. P. Burg, M. Godin, S. M. Knudsen, W. Shen, G. Carlson, J. S. Foster, Nature 2007, 446, 1066.

[14] G. Popescu, K. Park, M. Mir, R. Bashir, Lab Chip 2014, 14, 646.

[15] J. Krismer, J. Sobek, R. F. Steinhoff, S.n R. Fagerer, M. Pabst, R. Zenobi, Appl. Environ. Microbiol. 2015, 81, 5546.

[16] H. M. Nguyen, S. Cuiné, A. Beyly-Adriano, B. Légeret, E. Billon, Pa. Auroy, F. Beisson, G. Peltier, Y. Li-Beisson, Plant Physiol. 2013, 163, 914.

[17] T. Suzuki, H. Midonoya, Y. Shioi, Anal. Biochem. 2009, 390, 57.

[18] W. R. Riekhof, C. Benning, 'Glycerolipid Biosynthesis', in 'The Chlamydomonas Sourcebook' 2nd Ed., Chap. 2, Ed. E.H.H.B.S.B. Witman, 2009, Academic Press: London. pp. 41-68.

[19] E. G. Bligh, W. J. Dyer, Can. J. Biochem. Physiol. 1959, 37, 911.

[20] D. S. Gorman, R.P. Levine, Proc. Nat. Acad. Sci. USA 1965, 54, 1665.

[21] A. Vieler, C. Wilhelm, R. Goss, R. Süss, J. Schiller, Chem. Phys. Lipids 2007, 150, 143.

[22] L. Fouillen, B. Colsch, R. Lessire, 'The Lipid World Concept of Plant Lipidomics', in 'Advances in Botanical Research', Chap. 7, Ed. R. Dominique, 2013, Academic Press. pp. 331376. 